\title{
INVESTIGAÇÃO DE ACIDENTES BIOLÓGICOS ENTRE PROFISSIONAIS DE SAÚDE
}

\author{
Investigation of biological accidents among \\ health care workers
}

\section{Investigación de accidentes biológicos entre los trabajadores de la salud}

\author{
Juliana Azevedo da Silva \\ Adilson José de Almeida ${ }^{3}$
}

\author{
Vanessa Salete de Paula² \\ Livia Melo Villar ${ }^{4}$
}

\section{RESUMO}

Os objetivos deste trabalho foram identificar a principal categoria profissional exposta a risco biológico e os principais tipos de acidentes ocorridos entre trabalhadores da área de saúde, em Campos dos Goytacazes, RJ. A partir da análise das fichas de notificação de acidentes biológicos dos 183 profissionais acidentados entre janeiro de 2005 e setembro de 2005, observamos que a categoria profissional mais exposta foi a dos auxiliares/técnicos de enfermagem (54,1\%), seguida pela dos acadêmicos de medicina e odontologia (10,4\%). A ocorrência de acidentes com materiais perfurocortantes foi relacionada à manipulação frequente desses objetos e ao comportamento dos profissionais que utilizam práticas que oferecem riscos de acidentes com agulhas, tais como o descarte inadequado de objetos perfurocortantes.

Palavras-chave: Riscos Ocupacionais. Controle de Risco. Prevenção de Acidentes.

\section{Abstract}

The aims of this study were to identify the major professional category exposed to biological risk and the principal type of accident occurred among health care workers in Campos dos Goytacazes, RJ. Based on the analysis of 183 records filled out by the workers who suffered biohazardous accidents between January 2005 and September 2005, we found the nursing auxiliaries and technicians as the professional category more exposed to biohazardous accidents (54.1\%), followed by undergraduate medical and dental students (10.4\%). The occurence of acidents with piercing-cutting materials was related to frequent handling of these instruments, and to the behavior of workers who maintain practices providing risks of needlestick injuries, such as inappropriate disposal of piercing-cutting materials.

Key words: Occupational risk. Risk control. Accident prevention.

\section{Resumen}

El objetivo de este estudio fue identificar las principales categorías profesional expuestas a riesgos biológicos y el principal tipo de accidentes producidos entre los profesionales del área de la salud en Campos dos Goytacazes, RJ. Del análisis de 183 archivos de los trabajadores que sufren accidentes con material biológico, de enero a septiembre de 2005, se observó que la categoría profesional más expuesta a sufrir accidentes fue el de los auxiliares de enfermería $(54,1 \%)$, seguido por los estudiantes de odontología y medicina $(10,4 \%)$. La de accidentes se relacionó con la manipulación frecuente de agujas, y con el comportamiento de los trabajadores, que mantienen prácticas que ofrecen riesgos, como la eliminación inadecuada de agujas.

Palabras clave: Riesgos laborales. Control del riesgo. Prevención de accidentes.

\footnotetext{
'Aluna do Curso de Pós-Graduação em Análises Clínicas, Faculdade Redentor, Itaperuna, RJ. Bióloga, Laboratório de Referência Regional de Campos dos Goytacazes, Hospital Geral de Guarus, Campos dos Goytacazes, RJ. Brasil. E-mail: jazevedo silva@hotmail.com, ${ }^{2}$ Pesquisadora em Saúde Pública, Doutora em Ciências. Laboratório de Desenvolvimento Tecnológico em Virologia, Instituto Oswaldo Cruz, FIOCRUZ, Rio de Janeiro, RJ. Brasil. E-mail: vdepaula@ioc.fiocruz.br, ${ }^{3}$ Professor Adjunto, Doutor em Ciências. Setor de Hematologia da Clínica Médica "B" do Hospital Universitário Gaffrée e Guinle, Escola de Medicina e Cirurgia, UNIRIO, Rio de Janeiro. Brasil. E-mail:adilsonjoal@ig.com.br, ${ }^{4}$ Tecnologista em Saúde Pública, Doutora em Ciências. Laboratório de Hepatites Virais, Instituto Oswaldo Cruz, FIOCRUZ, Rio de Janeiro, RJ. Brasil. E-mail: Ivillar@ioc.fiocruz.br
} 


\section{INTRODUCÃO}

Acidentes resultantes de exposição ocupacional a materiais biológicos por trabalhadores da área de saúde têm sido considerados fator preocupante, não só pelos prejuízos que acarretam às instituições, mas também aos próprios trabalhadores ${ }^{1}$. A exposição ocupacional é caracterizada pelo contato direto com fluidos potencialmente contaminados e pode ocorrer de dois modos distintos: por inoculação percutânea, também chamada de parenteral; e pelo contato direto com pele e/ou mucosa, com comprometimento de sua integridade após arranhões, cortes ou por dermatites².

0 número de exposições ao sangue, incluindo aquelas percutâneas e mucocutâneas, varia conforme as diferentes categorias profissionais, as atividades realizadas pelo profissional e os setores de atuação dentro dos serviços de saúde. Profissionais de saúde da área cirúrgica, odontologistas, paramédicos e profissionais de setores de atendimento de emergência médica são considerados profissionais de alto risco de exposição ocupacional. 0 risco de exposição entre médicos varia de acordo com as diferentes especialidades. Entre os médicos que atuam em enfermarias de especialidades clínicas, o número estimado de exposições pode variar de 0,5 a 3,0 exposições percutâneas e 0,5 a 7,0 mucocutâneas por profissional/ano. Em médicos cirurgiões, são estimados $80 \mathrm{a}$ 135 contatos com sangue por ano, sendo 8 a 15 exposições percutâneas por ano $^{3}$.

Investigações de acidentes ocupacionais com material biológico entre profissionais da área de saúde mostraram que os que cuidam diretamente de pacientes são os mais expostos. Outros profissionais de categorias não envolvidas diretamente com os cuidados aos pacientes ou seus fluidos corporais também podem ser vítimas de acidentes biológicos, tais como trabalhadores de limpeza, lavanderia, manutenção e coleta de lixo ${ }^{4}$.

A partir da descrição do primeiro caso de infecção pelo vírus da imunodeficiência humana (Human Immunodeficiency Virus, ou HIV), foi dada mais ênfase às medidas preventivas contra infecções por patógenos transmitidos por sangue, atualmente chamadas de "Precauções-Padrão" 5 . As medidas de precauções-padrão são um conjunto de recomendações que visam prevenir a exposição ocupacional ao vírus da hepatite $B$ (Hepatitis $B$ Virus, ou HBV), vírus da hepatite $C$ (Hepatitis C Virus, ou HCV) e HIV em profissionais de saúde. De acordo com as medidas de precauções-padrão, recomendase a manipulação cuidadosa de objetos perfurocortantes por meio de ações como: evitar reencapar agulhas ou desconectálas de seringas antes do descarte, e descartar materiais perfurocortantes em recipientes apropriados. Além disso, recomenda-se também o uso de equipamentos de proteção individual (EPI), tais como: luvas, máscaras, protetores de olhos, nariz e boca, e jaleco/avental quando em contato direto com sangue ou fluidos corporais. Também são recomendações das precauções-padrão: a utilização de desinfetantes, como o hipoclorito de sódio, na limpeza de áreas com respingos de sangue ou outros materiais biológicos; os cuidados espećíficos no laboratório durante manipulação de amostras biológicas, como a utilização apenas de pipetas mecânicas; o transporte de materiais contaminados em embalagens impermeáveis e resistentes, e a marcação, com rótulos e etiquetas, de artigos médico-hospitalares e de exames coletados, identificando-os como material proveniente de pacientes com HIV/AIDS. Dentre as medidas específicas para a prevenção de infecções por patógenos provenientes do sangue ou outros fluidos corporais, apenas a vacina contra a hepatite B está disponível, com 90 a 95\% de eficácia ${ }^{6}$.

No Brasil, acidentes de trabalho devem ser comunicados imediatamente após sua ocorrência, por meio da emissão da Comunicação de Acidente de Trabalho (CAT), que deve ser encaminhada ao acidentado, ao hospital, ao sindicato da categoria correspondente, ao Sistema Único de Saúde (SUS), à Previdência Social e ao Ministério do Trabalho ${ }^{7}$. Entretanto, o problema dos acidentes de trabalho no Brasil tem proporções maiores do que as estatísticas existentes permitem estimar, tornando difíicil avaliar o seu dimensionamento real, inclusive quanto ao custo social. A principal fonte de dados estatísticos sobre acidentes de trabalho, no Brasil, é o Instituto Nacional de Seguridade Social (INSS), cujos dados oficiais se referem apenas aos acidentes ocorridos em trabalhadores segurados, não estando incluídos aqueles ocorridos em trabalhadores do setor informal, que representam importante parcela da população economicamente ativa. Não há, no momento, um sistema estabelecido de vigilância de acidentes de trabalho com material biológico. Os estudos existentes em nosso País referem-se a programas específicos realizados em hospitais universitários e em outros serviços de saúde, de forma individualizada, a partir de protocolos elaborados nessas unidades.

Observa-se grande dificuldade em se obter estimativas confiáveis da frequência de exposição ao sangue ou outros materiais biológicos envolvendo profissionais de saúde. Além da subnotificação das exposições por parte do profissional acidentado, a comparação entre as informações sobre as incidências de exposição é dificultada, em parte, pelos diferentes tipos de estudo realizados, como estudos de casos autorrelatados, estudos com questionários e entrevistas com os profissionais sobre as exposições ocorridas. 
Dessa forma, os objetivos do presente estudo foram identificar a principal classe de profissionais da área de saúde exposta a acidentes ocupacionais em um hospital, relacionar as potenciais práticas de risco envolvendo esses profissionais e propor estratégias para minimizar a exposição ocupacional dos profissionais à contaminação por materiais biológicos.

\section{METODOLOGIA}

Desenho do estudo: pesquisa descritiva de abordagem quantitativa. 0 estudo foi baseado na coleta de informações contidas em banco de dados do Laboratório de Referência Regional de Campos dos Goytacazes (LRRCG), do Hospital Geral de Guarus (HGG), localizado no município de Campos dos Goytacazes, Rio de Janeiro, Brasil. 0 LRRCG é uma unidade de patologia clínica (UPC) pertencente à rede pública municipal, onde são realizados exames laboratoriais para a população em geral, que se encontra em atendimento em nível ambulatorial, nos serviços de emergência e urgência do HGG. Nessa unidade também são realizadas análises sorológicas para HIV, HBV e HCV, incluindo testagem sorológica de indivíduos envolvidos em acidentes biológicos provenientes de outras unidades do município.

Coleta de dados: os dados foram obtidos a partir das notificações de acidentes biológicos realizadas entre janeiro de 2005 e setembro de 2005. Após a ocorrência de acidentes biológicos, os profissionais de saúde acidentados respondem a um questionário (Anexo) visando à notificação dos acidentes. Após a notificação do acidente, os questionários são encaminhados à UPC, juntamente com a amostra de soro e a solicitação de exames sorológicos (anti-HBC, anti-HBs, antiHCV e anti-HIV). 0 questionário continha informações como sexo, idade, profissão, tipo de exposição (percutânea, mucosa, ou pele sem haver perfuração); topografia da lesão (dedo da mão, outra área do membro superior que não os dedos, membros inferiores, olhos ou outro local, devendo este último ser especificado); tipo de material biológico envolvido (sangue, líquor, desconhecido quando proveniente de lixo, ou outro, que deve ser especificado); e o procedimento que deu origem ao acidente, como durante reencapamento de agulhas, punção venosa periférica, coleta de sangue e administração de anestesia, vacina ou medicamento subcutâneo, intramuscular ou intradérmico; e durante cirurgias, manuseio de lixo, descarte de material perfurocortante, ou outro, que deve ser especificado no questionário. As informações contidas nesse questionário foram registradas no banco de dados do LRRCG.

Informações sobre vacinação contra hepatite B e resposta vacinal (pelo teste anti-HBs) foram consideradas neste estudo para avaliação de fator de proteção dos profissionais de saúde no exercício de sua profissão. 0 profissional foi questionado sobre sua vacinação, se concluída ou em andamento, e, posteriormente, a sorologia anti-HBs foi realizada na UPC do HGG. Para proceder à análise, os acidentes foram classificados em categorias profissionais, tipo de material envolvido, tipo de exposição e situação de ocorrência (prática de risco e resultado do teste anti-HBs) .

Aspectos éticos: pacientes-fonte e profissionais envolvidos nos acidentes biológicos, cujos questionários não se apresentavam corretamente preenchidos, foram excluídos do estudo. A coleta dos dados para pesquisa foi realizada após anuência da coordenadora responsável pela UPC e do Diretor Administrativo de Apoio Técnico-Educacional do HGG, e aprovada pelo Comitê de Ética em Pesquisa da Faculdade Redentor, Itaperuna, RJ. Esta pesquisa foi realizada seguindo os princípios éticos contidos na Resolução no 196/96 do Conselho Nacional de Saúde (Brasil).

\section{RESULTADO}

Neste estudo, foram analisados 183 profissionais acidentados, $160(87,4 \%)$ eram profissionais que trabalhavam diretamente com pacientes e 23 (12,6\%) eram profissionais de apoio, que não estavam em contato direto com pacientes, como auxiliares administrativos, equipes de limpeza, funcionários de aterro sanitário. Na Tabela 1 são apresentadas as características dos profissionais de saúde ou apoio envolvidos em acidentes ocupacionais com material biológico potencialmente infectante. Quanto ao sexo, 156 $(85,2 \%)$ eram do sexo feminino e $27(14,8 \%)$ eram do sexo masculino. A média de idade dos profissionais acidentados foi de 33 anos $\pm 9,88$ anos (17 a 55 anos), sendo a maioria $(69,4 \%)$ com idade entre 20 e 40 anos. Maior freqüência de acidentes com material biológico foi registrada na categoria de auxiliares e técnicos de enfermagem $(54,1 \%)$, seguida de estudantes universitários dos cursos de medicina ou odontologia $(10,4 \%)$. Nenhum acidente ocupacional foi registrado na categoria de fisioterapeuta. 
Tabela 1: Características demográficas e ocupação dos profissionais de saúde ou de apoio $(n=183)$ envolvidos em acidentes de trabalho com material biológico, registrados no Laboratório de Referência Regional de Campos dos Goytacazes, RJ, no período de janeiro/2005 a setembro/2005

\begin{tabular}{lc}
\hline Característica & $n(\%)$ \\
\hline Sexo & $27(14,8)$ \\
Masc & $156(85,2)$ \\
Fem & \\
Idade (anos) & $33,0 \pm 9,8$ \\
Média \pm DP & $17-55$ \\
Variação & $7(3,8)$ \\
$<20$ & $127(69,4)$ \\
$20-40$ & $49(26,8)$ \\
$>40$ & $160(87,4)$ \\
Ocupaçāo & $6(3,3)$ \\
Com contato direto com paciente: & $4(2,2)$ \\
Médico & $13(7,1)$ \\
Enfermeiro & $99(54,1)$ \\
Odontologista & $8(4,4)$ \\
Fisioterapeuta & $9(4,9)$ \\
Auxiliar/Técnico de enfermagem & $19(10,4)$ \\
Auxiliar/Técnico de laboratório & $2(1,1)$ \\
Técnico de consultório dentório & $23(12,6)$ \\
Acadêmicos de Medicina ou Odontologia & $17(9,3)$ \\
Estagiários de nível médio (enfermagem ou patologia clínica) & $3(1,6)$ \\
Sem contato direto com paciente: & $3(1,6)$ \\
Equipe de limpeza & \\
Servidor de limpeza urbana/usina de reciclagem & \\
Funcionário administrativo & \\
\hline
\end{tabular}

A caracterização dos 183 acidentes avaliados revelou que a maioria (92,4\%; $n=169)$ ocorreu por exposição percutânea, $84,6 \%$ atingindo principalmente dedos e 86,3\% envolvendo sangue como material biológico (Tabela 2). 0 procedimento de punção venosa periférica foi a prática mais frequentemente $(15,8 \%)$ envolvida nos acidentes, seguida da cirurgia $(15,3 \%)$ e manuseio do lixo (13,7\%). Outros procedimentos, como manuseio de tubo de vidro quebrado contendo sangue, lavagem de instrumentos cirúrgicos, manuseio de caixa com material perfurocortante, descarte de material perfurocortante em local inadequado e retirada de pontos de sutura, foram responsáveis por 31 (17\%) acidentes notificados.

Tabela 2: Características dos acidentes de trabalho com material biológico $(n=183)$ registrados no Laboratório de Referência Regional de Campos dos Goytacazes, RJ, no período de janeiro/2005 a setembro/2005

\begin{tabular}{lc}
\hline Característica & $n(\%)$ \\
\hline Tipo de Exposiçāo & $169(92,4)$ \\
Percutânea & $9(4,9)$ \\
Mucosa & $5(2,7)$ \\
Pele & $155(84,6)$ \\
Topografia da lesão & $14(7,7)$ \\
Dedo da mão & $4(2,2)$ \\
Outra área do membro superior & $8(4,4)$ \\
Membros inferiores & $2(1,1)$ \\
Olhos & \\
Outra & $158(86,3)$ \\
Tipo de material biológico & $0(0,0)$ \\
Sangue & $0(0,0)$ \\
Líquor & $23(12,6)$ \\
Líquido pleural/pericárdico/articular/amniótico & $2(1,1)$ \\
Desconhecido' & \\
Outro & $29(15,8)$ \\
Situação & $28(15,3)$ \\
Durante punção venosa periférica & $25(13,7)$ \\
Durante cirurgias & $23(12,6)$ \\
Durante manuseio de lixo & $21(11,5)$ \\
Administração de vacinas, anestesias ou medicamentos via IM/SC/ID & $18(9,8)$ \\
Durante descarte de material perfurocortante & $8(4,4)$ \\
Durante recapeamento de agulhas & $31(17,0)$ \\
Durante coleta de sangue &
\end{tabular}

${ }^{1}$ Material não identificado, encontrado no lixo. IM, intramuscular; SC, subcutânea; ID, intradérmica. 
A ficha de notificação não contém informações quanto ao uso de EPI pelo profissional durante a realização de procedimentos que resultaram em acidente. Todavia, questiona sobre a proteção para uma das principais infecções relatadas em acidentes com material biológico, a vacina contra hepatite B. Com relação aos 167 (91,3\%) indivíduos com imunização prévia contra hepatite B, $136(74,3 \%)$ apresentavam resposta vacinal (anti-HBs positivos).

Com relação aos principais procedimentos que levaram aos acidentes nos profissionais de enfermagem, verificamos que a maioria dos acidentes ocorreu durante a prática de punção venosa periférica (27,3\%), principalmente para fixação de cateter para administração de soro fisiológico e medicamentos (Figura 1). Em relação aos estudantes de medicina e odontologia, observamos que a atividade de cirurgia e o reencapamento de agulhas foram os principais motivos de acidentes (Figura 2).

Figura 1: Distribuição dos acidentes de trabalho com material biológico envolvendo auxiliar/técnico de enfermagem ( $n=99)$ em relação à situação do acidente, registrados no Laboratório de Referência Regional de Campos dos Goyłacazes, RJ, no período de janeiro/2005 a setembro/2005



Figura 2: Distribuição dos acidentes de trabalho com material biológico envolvendo acadêmicos de medicina ou odontologia $(n=19)$ em relação à situação do acidente, registrados no Laboratório de Referência Regional de Campos dos Goytacazes, RJ, no período de janeiro/2005 a setembro/2005

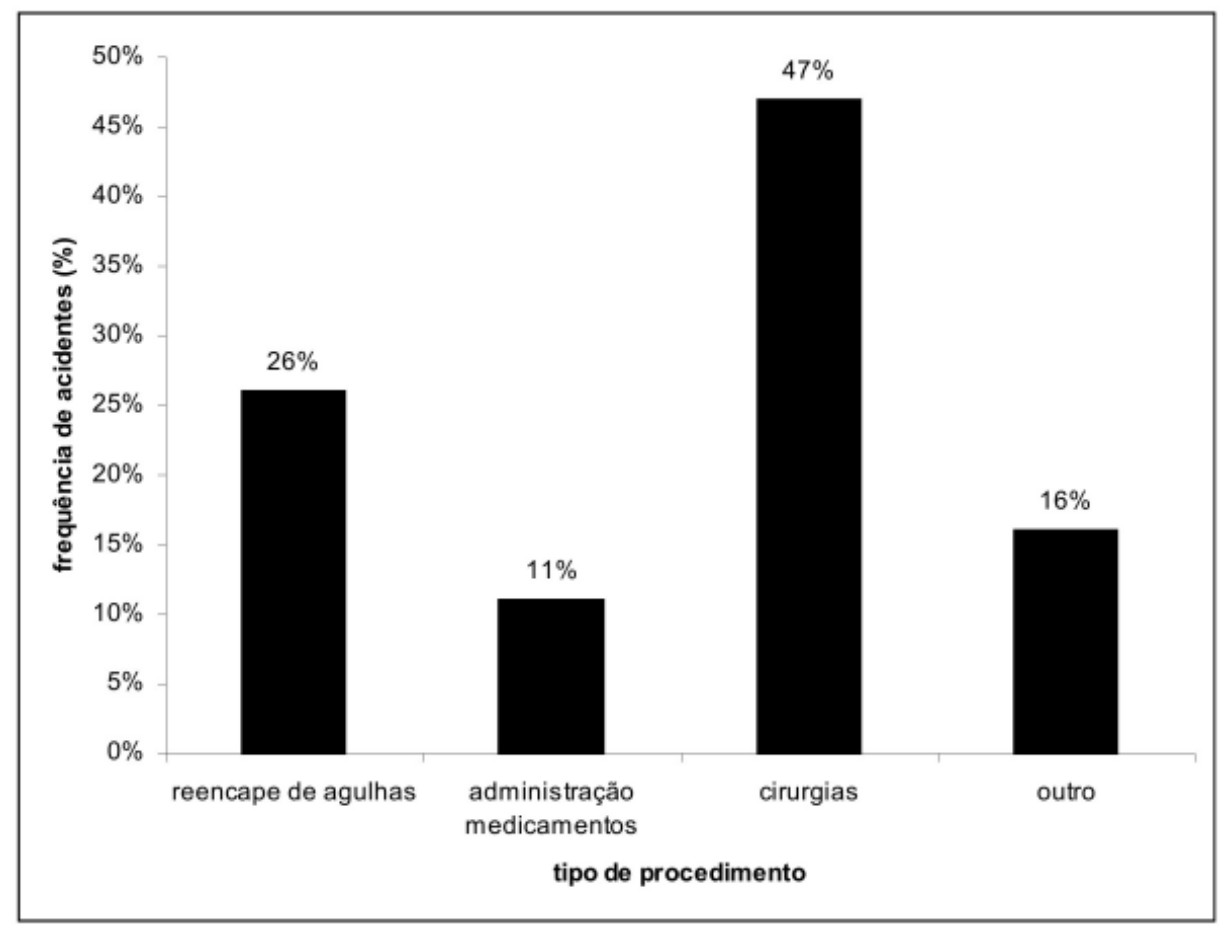




\section{DISCUSSÃO}

Os acidentes ocupacionais são definidos como danos ocorridos devido ao desenvolvimento das atividades no local de trabalho, causando alteração funcional e/ou lesão corporais ao trabalhador. Geralmente, esses danos resultam em interrupção das atividades trabalhistas, um evento que pode ser traumático para vítima e seus colegas, os quais estão frequentemente sujeitos aos mesmos riscos. Além disso, acidentes ocupacionais constituem prejuízo para a empresa, levando à redução do número de trabalhadores por hora trabalhada e, assim, à perda da produção e aumento do custo por unidade produzida ${ }^{8}$.

A notificação com informações completas é importante para identificação de práticas desenvolvidas pelo profissional que impõem ao mesmo um risco ocupacional. Esse risco pode ser minimizado por meio da realização de estudos que desenvolvam estratégias que ajudem aos profissionais a se conscientizarem das práticas de risco de exposição às doenças infecciosas ocupacionais, e também pela identificação dos EPI para proteção adequada durante o exercício de suas atividades, específicas de cada profissional. Cabe ao empregador fornecer esses equipamentos e cabe ao profissional solicitá-los e, quando recebê-los, usá-los corretamente, conforme previsto na norma regulamentadora 6 do Ministério do Trabalho.

No presente estudo, maior frequência de acidentes com material biológico foi registrada na categoria de trabalhadores de enfermagem (auxiliares e técnicos), 54,1\%. Na casuística de Chiodi e colaboradores, 42/155 (67,7\%) acidentes em trabalhadores de unidades de saúde pública do município de Ribeirão Preto, SP, foram registrados na categoria de auxiliares e técnicos de enfermagem 9 . De acordo com Bulhões, o contingente de trabalhadores de enfermagem, particularmente aquele inserido no contexto hospitalar, permanece 24 horas em contato com pacientes ou auxiliando em procedimentos hospitalares. Dessa forma, esses profissionais estão expostos a vários riscos potenciais, podendo adquirir doenças ocupacionais, além de lesões em decorrência dos acidentes de trabalho ${ }^{10}$.

Estudantes universitários dos cursos de medicina ou odontologia, os quais tomam parte na realização de diversos procedimentos sob supervisão, constituíram a segunda categoria mais frequente $(10,4 \%)$ em relação aos acidentes. Nenhum acidente ocupacional foi registrado para a categoria de fisioterapeuta, que é uma classe que está em contato direto com pacientes, porém usualmente não há manipulação de sangue ou outros fluidos corporais dos pacientes sob seus cuidados. Deisenhammer e colaboradores, em estudo transversal envolvendo 1.317 estudantes de escolas médicas da Alemanha, relataram prevalência de $23 \%$ de acidentes com agulhas, variando de $12 \%$ em estudantes do primeiro ano do curso de medicina a $41 \%$ naqueles do quarto ano do curso ${ }^{11}$. Tal proporção de acidentados em estudantes desses cursos pode estar associada à falta de conhecimento adequado sobre medidas de precauções universais e treinamento repetido sob supervisão apropriada, bem como ao nervosismo e/ou inexperiência do estudante durante o procedimento cirúrgico, situação da maioria dos acidentes notificados nessa classe. Em outro estudo transversal, objetivando avaliar o conhecimento sobre HIV/AIDS de 642 estudantes de odontologia do Sudão, foi demonstrado que apenas $38 \%$ dos estudantes apresentavam conhecimento adequado sobre diferentes grupos de risco ocupacional para HIV/AIDS ${ }^{12}$.

0 manuseio de resíduos biológicos infecciosos constitui problema não apenas para os trabalhadores de enfermagem. Os estudantes de enfermagem no exercício das práticas clínicas sofrem com a incerteza e o medo de contrair doenças infectocontagiosas, por não saberem manusear estes resíduos corretamente. Além disso, foi demonstrado que os mesmos sentem indiferença por não acreditar que existe perigo de contaminação por materiais biológicos infecciosos e vergonha em relação a eventuais críticas que possam receber como resultado de práticas inadequadas ${ }^{13}$.

Em relação à situação durante a qual ocorreu o acidente biológico, Marziale e colaboradores relataram maior frequência (34\%) de perfuração com agulha durante punção venosa dentre diferentes tipos de acidente com material perfurocortante em trabalhadores de enfermagem atendidos em um serviço especializado no tratamento de doenças infecciosas de um hospital universitário do município de Ribeirão Preto, $\mathrm{SP}^{14}$. Em nosso estudo, observamos que a punção venosa periférica foi o procedimento que mais frequentemente resultou na ocorrência de acidentes ocupacionais com material biológico em nossa casuística. Além disso, observamos que a maioria dos acidentes de trabalho com material biológico envolvendo os trabalhadores de enfermagem (auxiliares e técnicos) foi, também, devida à punção venosa. Entretanto, a investigação sobre o uso de EPI em trabalhadores de enfermagem foi prejudicada em nossa série visto que essa questão não constava do questionário durante a notificação. No entanto, a ocorrência de acidentes envolvendo mucosa (ocular e oral) em uma proporção dos acidentados parece indicar que uma parcela desses profissionais não utilizava EPI, como máscara e óculos de proteção.

A maioria dos acidentes causados por agulhas descartadas em lugares inadequados parece refletir a falta de cuidado do profissional da área de saúde com relação ao descarte desses materiais, não apenas com sua própria segurança, mas também com a segurança de profissionais de outras áreas, os quais deveriam ser menos expostos a esses acidentes ${ }^{15}$. No presente estudo, cinco dos sete casos de acidentes por descarte de material perfurocortante em local inadequado envolveram profissionais da classe dos auxiliares e técnicos de enfermagem. 0 registro de acidentes com materiais perfurocortantes em funcionários de aterro sanitário e da 
equipe de limpeza hospitalar parece também revelar o descuido dos profissionais de saúde que trabalham em unidades de atendimento de pacientes, pois, ao descartarem instrumentos de forma inadequada, expuseram outros profissionais a riscos biológicos.

0 conhecimento sobre a situação/atividade relacionada ao acidente biológico em estudantes ou trabalhadores da área de saúde pode contribuir para a revisão e elaboração de estratégias de prevenção dos acidentes ocupacionais envolvendo materiais biológicos, conforme demonstrado em estudos prévios 9116,17 .

Com relação à proteção contra hepatite $\mathrm{B}$, a maioria dos acidentados relatou vacinação prévia $(91,3 \%)$, entretanto somente $73 \%$ apresentaram resultado reagente para 0 anticorpo anti-HBs. Isto indica que muitos profissionais não estão protegidos contra a infecção pelo HBV, provavelmente porque não completaram o esquema vacinal ou não apresentaram resposta vacinal. Reis e colaboradores ${ }^{18}$ também relataram taxa elevada (96\%) de adesão ao esquema vacinal em profissionais envolvidos em acidentes biológicos, porém não foi avaliada a resposta vacinal em sua coorte, não descartando assim a possibilidade de menor taxa de imunoproteção quando avaliada pela aquisição de anticorpos anti-HBs.

A percepção do risco pelo trabalhador influencia o seu comportamento e, consequentemente, a sua exposição aos riscos. A prevenção depende, em parte, dessa identificação dos riscos ${ }^{19}$. Estudo recente revelou que uma proporção dos profissionais de enfermagem do setor de clínica médica de um hospital militar do município do Rio de Janeiro estaria exposta ao risco de contrair a hepatite $B$ caso ocorresse acidente com material perfurocortante, uma vez que um número significativo deles não havia recebido treinamento de como proceder caso houvesse um acidente com material perfurocortante, além de desconhecer as formas de transmissão da hepatite B e medidas de biossegurança ${ }^{20}$.

Para minimização dos acidentes biológicos ocupacionais é importante que seja elaborado e executado um programa de educação continuada para profissionais da área de saúde que trabalham direta ou indiretamente com pacientes. Esse programa deve abordar a questão da exposição ao material biológico e dos acidentes biológicos, esclarecendo sobre a importância da adoção de medidas de precauções-padrão e normas de biossegurança, vacinação contra hepatite $B$, da notificação do acidente e do atendimento médico até 2 horas após 0 acidente.

Os acidentes com agulhas constituem a principal forma de exposição percutânea acidental dos profissionais de saúde às infecções como HIV/AIDS, hepatites B eC. É questão prioritária, portanto, a adoção de medidas de prevenção e controle de riscos ocupacionais relacionados aos acidentes com agulhas, que deve se iniciar com análise cuidadosa das fontes potenciais de risco, procurando-se caracterizar as situações de ocorrência e os padrões de tendências ${ }^{16}$.

\section{CONCLUSÕES}

Podemos concluir que as classes profissionais mais acometidas por acidentes biológicos são os auxiliares e técnicos de enfermagem, e acadêmicos de medicina e odontologia. A ocorrência de acidentes com materiais perfurocortantes, neste estudo, está relacionada a dois aspectos: (1) manipulação frequente de objetos perfurocortantes, característica peculiar da ocupação profissional, justificando o grande número de acidentes relacionados à realização ou auxílio de procedimentos; e (2) o comportamento dos profissionais que continuam mantendo práticas de riscos de acidentes com agulhas, como o descarte inadequado de objetos perfurocortantes, importante fonte de risco para acidentes ocupacionais, até mesmo para grupos de profissionais que não estão em contato direto com o paciente, como funcionários da limpeza. Por fim, para reduzir a frequência de acidentes com material biológico neste grupo de profissionais, seria necessária a realização de cursos de atualização em biossegurança a todos os profissionais atuantes na área da saúde, principalmente em ambientes hospitalares, visando aumentar o conhecimento sobre as medidas de precauçõespadrão por parte desses profissionais.

\section{REFERÊNCIAS}

1.Sailer GC, Marziale MHP. Vivência dos trabalhadores de enfermagem frente ao uso dos anti-retrovirais após exposição ocupacional a material biológico. Texto Contexto Enferm 2007 jan/mar; 16 (1): 5562.

2.Decher MD. The OSHA bloodborne hazard standard. Infect Control Hosp Epidemiol 1992 Jul; 13 (7): 407-17.

3.Rapparini C, Vitória MAA, Lara LTR. Recomendações para atendimento e acompanhamento de exposição ocupacional a material biológico: HIV e hepatites B e C. [on-line] 2007; [citado 21 jan 2007]. Disponível em: http://www.riscobiologico.org/resources/4888.pdf.

4.Canini SRMS, Gir E, Machado AA. Accidents with potentially hazardous biological material among workers in hospital supporting services. Rev Latino-am Enfermagem 2005 jul/ago; 13 (4): 496-500.

5.Needle stick transmission of HTLV-III from a patient infected in Africa. Lancet 1984 Dec; 2 (8416): 1376-77.

6.Garner JS. Guideline for isolation precautions in hospitals. Guideline for isolation precautions in hospitals. The Hospital Infection Control Practices Advisory Committee. Infect Control Hosp Epidemiol 1996 Jan; 17 (1): 53-80.

7.Marcelino IV. 0 sistema de informações sobre acidentes do trabalho no Município de Ribeirão Preto, São Paulo, Brasil, no ano de 1998: uma abordagem qualitativa. [dissertação de mestrado]. Ribeirão Preto (SP): Faculdade de Medicina /USP; 1999.

8.Cordeiro R. Suggestion of an inverse relationship between perception of occupational risks and work-related injuries. Cad Saude Publica $2002 \mathrm{jan} / \mathrm{fev} ; 18$ (1): 45-54.

9.Chiodi MB, Marziale MHP, Robazzi MLCC. Occupational accidents involving biological material among public health workers. Rev Latinoam Enfermagem 2007 jul/ago; 15 (4): 632-38.

10.Bulhões I. Riscos do trabalho de enfermagem. Rio de Janeiro(RJ): Folha Carioca; 1998. 221p. 
11.Deisenhammer S, Radon K, Nowak D, Reichert J. Needlestick injuries during medical training. J Hosp Infect 2006 Jul; 63 (3): 263-67.

12.Nasir EF, Astrøm AN, David J, Ali RW. HIV and AIDS related knowledge, sources of information, and reported need for further education among dental students in Sudan: a cross sectional study. BMC Pub Health 2008 Aug; 14; 8: 286.

13.Rubio MO, Ávila GA, Gómez BA. Actitudes de estudiantes de enfermería mexicanos al manejar residuos peligrosos biologico infecciosos. Esc Anna Nery Rev Enferm 2008 set; 12 (3): 479-84.

14.Marziale MHP, Nishimura KYN, Ferreira MM. Riscos de contaminação ocasionados por acidentes de trabalho com material pérfuro-cortante entre trabalhadores de enfermagem. Rev Latino-am Enfermagem 2004 jan/fev; 12 (1): 36-42.

15.Brevidelli MM, Cianciarullo TI. Análise dos acidentes com agulhas em um hospital universitário: situações de ocorrência e tendências. Rev Latino-am Enfermagem 2002 nov/dez; 10 (6): 780-86.
16. Balsamo AC, Felli VEA. Estudo sobre os acidentes de trabalho com exposição aos líquidos corporais humanos em trabalhadores da saúde de um hospital universitário. Rev Latino-am Enfermagem 2006 maio/ jun; 14 (3): 346-53.

17.Gir E, Caffer Netto J, Malaguti SE, Canini SRMS, Hayashida M, Machado AA. Accidents with biological material and immunization against hepatitis $B$ among students from the health area. Rev Latino-am Enfermagem 2008 maio/jun; 16 (3): 401-16.

18. Reis RK, Gir E, Canini SRMS. Accidents with biological material among undergraduate nursing students in a public brazilian university. Braz J Infect Dis 2004 Feb; 8 (1):18-24.

19.Schilling RS. Health protection and promotion at work. $\mathrm{Br} J$ Ind Med 1989 Oct; 46 (10): 683-88.

20.Pinheiro J, Zeitoune RCG. Hepatite B: conhecimento e medidas de biossegurança e a saúde do trabalhador de enfermagem. Esc Anna Nery Rev Enferm 2008 jun; 12 (2): 258-64.

Notas

\section{Colaboradores}

J. A. da Silva participou da coleta, tabulação e redação do artigo; V.S. de Paula participou no desenvolvimento da pesquisa, colaborou na análise dos dados e na redação do artigo; A.J. de Almeida colaborou na análise estatística e na redação do artigo; L.M. Villar participou na idealização, no desenvolvimento da pesquisa e na redação do artigo.

\section{Agradecimentos}

À Dra . Luciana Cordeiro de Araújo, Coordenadora da Unidade de Patologia Clínica (UPC) do Hospital Geral de Guarus (HGG), e ao Dr. Alberto Cruz P. Carvalho, Diretor Administrativo de Apoio Técnico Educacional do HGG, por disponibilizarem o acesso ao banco de dados da UPC/HGG para análise dos questionários referentes aos acidentes biológicos notificados. 


\section{ANEXO 1}

Figura 1: Ficha de notificação de acidente de trabalho com material biológico

1. Nome:

2. Sexo: [ ] F [ ] M

3. Data de nascimento/ldade:

4. Endereço:

5. Telefone para contato:

6. Ocupação:
(A) (A) Médico
(B) Enfermeiro
(H) Acadêmicos de Medicina ou
(C) Odontologista Odontologia
(D) Fisioterapeuta
(I) Estagiários de nível médio
(E) Auxiliar/Técnico de enfermagem
(F) Área de laboratório
(J) Técnico de consultório dentário
(G) Equipe de limpeza
(K) Servidor de limpeza urbana/usina de reciclagem
(L) Funcionário administrativo

1. 7. Nome da unidade de ocorrência do acidente:

8. Nome da unidade que forneceu medicação antirretroviral inicial:

9. Data de ocorrência do acidente:

10. Hora de ocorrência do acidente:

11. Data de notificação:

12. Hora de notificação:

13. Tipo de exposição:
(A) Percutânea
(B) Mucosa (olhos, boca, nariz, ou genitália)
(C) Pele (somente contato com pele, sem haver perfuração)

14. Tipo de material biológico envolvido na exposição:
(A) (A) Sangue
(B) Líquor
(C) Líquido pleural
(D) Líquido pericárdico
(E) Líquido articular

(F) Líquido amniótico

(G) Desconhecido (material não identificado, encontrado no lixo)

(H) Outro - especificar

1. $\quad$ 15. Topografia da lesão:
(A) (A) Dedo da mão
(D) Olhos
(B) Outra área do membro superior
(E) Outra - especificar
(C) Membros inferiores

1. 16. Situação:
(A) (A) Recapeamento de agulhas
(F) Manuseio de lixo
(B) Durante punção de veia periférica
(G) Durante o descarte do material perfurocortante
(C) Durante coleta de sangue
(H) Outra - especificar
(D) Administração venosa de anestesias
(E) Durante cirurgias

1. 17. Situação sorológica do paciente-fonte:

18. Paciente-fonte desconhecido (material em lixo, área de expurgo):
(A) Paciente-fonte identificado como anti-HIV+
(B) Sorologias não conhecidas para hepatites B, C e HIV
(C) Paciente-fonte conhecido e sabidamente anti-HIV+
(D) Paciente-fonte conhecido e sabidamente HBsAg + (Hepatite B)
(E) Paciente-fonte conhecido e sabidamente anti-HCV+ (Hepatite C)
(F) Paciente-fonte conhecido e sorologias recentes negativas para hepatites B, C e HIV

19. Foi feito teste rápido para HIV?

20. Situação do profissional acidentado: Vacinado contra hepatite B?
(A) Não
(B) Não sabe informar
(C) Sim, 1 dose
(D) Sim, 2 doses
(E) Sim, 3 doses 